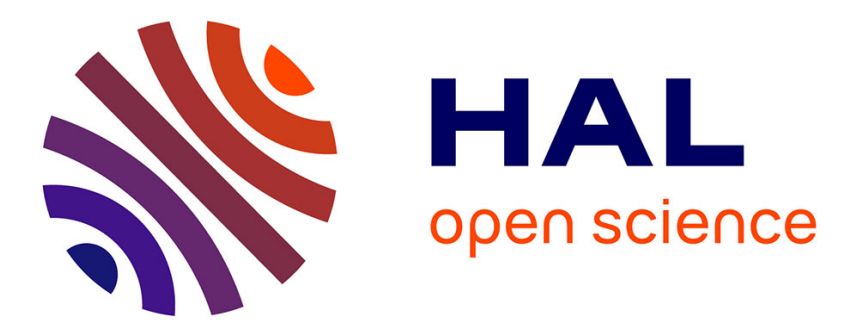

\title{
POTENTIAL MISINTERPRETATION OF INFANT LUNG FUNCTION UNLESS PROSPECTIVE HEALTHY CONTROLS ARE STUDIED
}

Sooky Lum, Ah-Fong Hoo, Georg Huelskamp, Angie Wade, Janet Stocks

\section{- To cite this version:}

Sooky Lum, Ah-Fong Hoo, Georg Huelskamp, Angie Wade, Janet Stocks. POTENTIAL MISINTERPRETATION OF INFANT LUNG FUNCTION UNLESS PROSPECTIVE HEALTHY CONTROLS ARE STUDIED. Pediatric Pulmonology, 2010, 45 (9), pp.906. 10.1002/ppul.21255 . hal-00557755

\section{HAL Id: hal-00557755 \\ https://hal.science/hal-00557755}

Submitted on 20 Jan 2011

HAL is a multi-disciplinary open access archive for the deposit and dissemination of scientific research documents, whether they are published or not. The documents may come from teaching and research institutions in France or abroad, or from public or private research centers.
L'archive ouverte pluridisciplinaire HAL, est destinée au dépôt et à la diffusion de documents scientifiques de niveau recherche, publiés ou non, émanant des établissements d'enseignement et de recherche français ou étrangers, des laboratoires publics ou privés. 


\section{POTENTIAL MISINTERPRETATION OF INFANT LUNG FUNCTION UNLESS PROSPECTIVE HEALTHY CONTROLS ARE STUDIED}

\begin{tabular}{|r|l|}
\hline Journal: & Pediatric Pulmonology \\
\hline Manuscript ID: & PPUL-09-0436.R1 \\
\hline Diley - Manuscript type: & Original Article \\
\hline Author: & 24-Feb-2010 \\
\hline & $\begin{array}{l}\text { Complete List of Authors: } \\
\text { Huelskamp, Georg; Universitätsklinikum and Clemenshospital, } \\
\text { Department of Paediatrics } \\
\text { Wade, Angie; Centre for Paediatric, Epidemiology and Biostatistics } \\
\text { Unit } \\
\text { Stocks, Janet; UCL, Institute of Child Health, Portex Respiratory } \\
\text { Unit }\end{array}$ \\
\hline Keywords: & $\begin{array}{l}\text { Infant, forced expiratory maneuvers, pulmonary function test, } \\
\text { Reference values, equipment }\end{array}$ \\
\hline
\end{tabular}

\section{s scholaroNE" \\ Manuscript Central}




\section{POTENTIAL MISINTERPRETATION OF INFANT LUNG FUNCTION UNLESS PROSPECTIVE HEALTHY CONTROLS ARE STUDIED}

Sooky Lum, PhD ${ }^{1}$; Ah-Fong Hoo, PhD ${ }^{1,2}$; Georg Hulskamp, $\mathrm{MD}^{3}$; Angie Wade, PhD ${ }^{4}$ and Janet Stocks, PhD ${ }^{1}$

${ }^{1}$ Portex Unit: Respiratory Physiology and Medicine, UCL, Institute of Child Health, London, ${ }^{2}$ Great Ormond Street Hospital for Children NHS Trust, London, ${ }^{3}$ Department of Paediatrics, Universitätsklinikum and Clemenshospital, Münster, Germany and ${ }^{4}$ Centre for Paediatric Epidemiology and Biostatistics Unit, London, UK.

Funding source: Medical Research Council, UK; Cystic Fibrosis Trust; British Lung Foundation. Research at the Institute of Child Health and Great Ormond Street Hospital for Children NHS Trust benefits from R\&D funding received from the NHS Executive.

Corresponding author: Sooky Lum

Portex Respiratory Unit

UCL, Institute of Child Health

30 Guilford Street

London WC1N 1EH

Email: $\underline{\text { s.lum@ich.ucl.ac.uk }}$

Tel: +44 (0)20 $79052382 \quad$ Fax: +44 (0)20 78298634

Reprints are not available from the authors.

Abbreviated title: Lung function in healthy infants

This article has an online data supplement. 


\section{SUMMARY}

Rationale: Reliable interpretation of pulmonary function tests relies on appropriate reference data which remain very limited for infants.

Objectives: This study aimed to assess the validity of published reference equations for forced expiratory flow-volume (FEFV) data in infants when using current, commercially available equipment, and how this could impact on interpretation of results from infants with lung disease.

Methods: The Jaeger Masterscreen BabyBody (v4.67) equipment was used to perform partial and raised volume FEFV maneuvers in healthy infants and those with cystic fibrosis $(\mathrm{CF})$. Results were initially expressed as Z-scores using published reference equations. Multilevel modelling was used to calculate differences, if any, from predicted scores in healthy infants.

Results: Data were available from 66 healthy fullterm infants on 89 test occasions; [median (range) postnatal age 49.4(12-101) weeks. All FEFV outcomes were significantly lower than predicted, with mean (SD) Z-score differences of -0.4(1.1) for $\mathrm{FVC}$; -0.6(1.0) for $\mathrm{FEV}_{0.5} ;-1.0(1.0)$ for $\mathrm{FEF}_{25-75}$ and -1.4(1.1) for $\mathrm{V}^{\prime}{ }_{\text {maxFRC. }}$ After adjustments using multilevel modelling, mean Z-scores were within $0.1(\mathrm{SD} 1.0)$ predicted for all outcomes in healthy infants. Among 50 infants with CF, studied on 85 test occasions, results were 'abnormal' (<-1.96 Z-scores) on $35(41 \%)$ and $37(45 \%)$ test occasions for $\mathrm{FEV}_{0.5}$ and $\mathrm{FEF}_{25-75}$ respectively when using published equations. This fell to $24(28 \%)$ and $20(24 \%)$ respectively, after adjustment.

Conclusions: Dependence on published equations for interpreting FEFV data in infants may lead to misinterpretation of lung function status, which could impact adversely both in the research setting and on clinical management. Use of a contemporary control group or establishment of equipmentspecific reference data is essential for meaningful interpretation of infant lung function data.

Keywords: Infant; forced expiratory maneuvers; pulmonary function test; Reference values; equipment 


\section{INTRODUCTION}

Assessments of forced expiration have been used extensively in older children and adults to assess the nature and severity of airway disease, response to therapeutic intervention and to monitor disease progression or resolution in both the clinical and research environments. While infants cannot be instructed to perform such maneuvers, forced expiratory flow-volume (FEFV) loops can be obtained by substituting voluntary effort with externally applied pressure to the chest and abdomen to force expiration. Measurements of maximal flow at functional residual capacity $\left(V_{\operatorname{maxFRC}}\right)$ from the tidal rapid thoraco-compression technique (RTC) have been used to characterize growth and development of the airways during infancy ${ }^{1-3}$ and, together with data derived from the raised volume RTC (RVRTC), have been found to discriminate clearly between health and disease within the research setting. ${ }^{4-8}$ Nevertheless, if such tests are to be used in clinical management, reliable reference ranges are also required.

While prediction equations have been published for infant FEFV outcomes, 9,10 these were derived from children studied using equipment developed 'in-house' and the extent to which they remain appropriate for current, commercially available equipment that was introduced following recommendations from the ATS-ERS task force on infant lung function ${ }^{11-13}$ has yet to be determined. The need to assess whether selected prediction equations are appropriate for a given population or specific equipment is well-recognized, ${ }^{14-16}$ but has rarely been done in infants due to the time-consuming nature of these tests and need for sedation. In addition, increasing difficulty in obtaining ethics committee approval for sedating healthy infants during the past decade has severely limited the extent to which normal growth and development of infant lung function can be assessed in several countries, including the USA.

The aims of this study were to: a) assess whether FEFV results obtained from healthy infants using the current Jaeger equipment differ from predicted values, b) investigate whether, in the event of any significant offset, it would be possible to adjust for any equipment-specific differences in order 
to facilitate interpretation in infants with lung disease and c) evaluate the impact of applying such a correction factor to a cohort of infants with cystic fibrosis (CF) studied using identical equipment and techniques. Some of the results included in this study have been reported previously. ${ }^{5,17}$ 


\section{MATERIALS AND METHODS}

The study population was comprised of:

a) healthy fullterm (>37 gestational weeks) white infants without congenital abnormalities or respiratory compromise (i.e. no current respiratory problems or history of respiratory illness requiring hospitalization) who had been recruited to epidemiological studies or as controls for clinical research $^{5,17,18}$ and

b) Infants diagnosed with CF without severe congenital, cardiovascular or neuromuscular disorders that could impact on the respiratory system, who had been recruited to clinical research studies. ${ }^{5}$ Children with a history of apneic episodes or upper airway pathology were excluded. Local Research Ethics Committee approval was granted and written informed parental consent was obtained for all infants.

Equipment and study protocol: With the exception of two infants with CF who had had repeated respiratory exacerbations and were therefore tested as soon as asymptomatic for 14 days, lung function tests in all children were undertaken at least 3 weeks after any respiratory illness. Data were collected during quiet sleep, after oral sedation with chloral hydrate $(50-100 \mathrm{mg} / \mathrm{kg}$ depending on age). RTC and RVRTC data were collected using the Jaeger Masterscreen BabyBody System (CareFusion, San Diego). This equipment was designed in adherence with the ATS-ERS recommendations ${ }^{11-13}$ and uses a low deadspace pneumotachometer with solid-state transducers. Tidal and raised volume maneuvers were performed in accordance with international recommendations ${ }^{11,12}$ as previously described, ${ }^{19,}{ }^{20}$ with the tidal RTC being performed prior to raised volume maneuvers. ${ }^{21}$ The RVRTC was performed from an inflation pressure of $30 \mathrm{cmH}_{2} \mathrm{O}$, the maneuver being repeated until a minimum of three acceptable and reproducible FEFV curves was obtained. Forced expiratory volume in 0.5 second $\left(\mathrm{FEV}_{0.5}\right)$, forced vital capacity (FVC), forced expiratory flow when $75 \% \mathrm{FVC}$ had been expired $\left(\mathrm{FEF}_{75}\right)$ and $\mathrm{FEF}$ between $25-75 \% \mathrm{FVC}\left(\mathrm{FEF}_{25}\right.$ 75) were reported from the "best" raised volume curve. The latter was defined as the technically 
acceptable forced expiratory FEFV curve with the highest sum of FVC and FEV ${ }_{0.5}{ }^{11}$ For RTC, the mean $V_{\text {maxFR }}^{\prime}$ from at least two (usually three) reproducible FEFV curves was reported. ${ }^{12}$

\section{Statistical Analysis}

Power calculations demonstrated that FEFV measurements from 65 healthy children would enable differences equivalent to $0.4 \mathrm{SD}$ (or Z-scores) to be detected between the controls and the published reference population with $90 \%$ power at the 0.05 significance level. Standard software packages were used for data inspection, distribution and descriptive statistics (SPSS for Windows, v15.0, SPSS Inc.). Results from healthy controls were expressed as Z-scores using published prediction equations. ${ }^{9,10}$ To ensure that we would still be able to detect differences between those exposed to maternal smoking during pregnancy compared to those who were not, the calculation of Z-scores for RVRTC data was made with smoking status during pregnancy being set to 0 (zero). The extent to which these Z-scores differed from zero according to sex, age and body size was inspected and univariable regression analysis was used to establish the association between each FEFV outcome and likely explanatory variables. Where potentially significant associations existed, these were further explored using multivariable, multilevel regression modeling (MLwiN, version 2.12; Institute of Education, UK). These highly flexible models adjust for the correlated nature of repeated measurements in individuals and allow inclusion of variable numbers of measurements per child to provide the most precise characterization of changes over time. ${ }^{22-24}$ To quantify the extent to which age or length was independently associated, after adjusting for factors accounted for by the Jones and Hoo equations ${ }^{9,10}$, a stepwise approach was used in developing the multivariable models: each dependent (FVC, $\mathrm{FEV}_{0.5}$ etc) was adjusted for potential determinants such as length, age, sex etc. The derived regression equations for the LF variables were then applied to results from children with $\mathrm{CF}$ to evaluate the potential impact of applying such an adjustment factor on clinical management. Data management was undertaken using Re-Base software (J7IS Ltd). 


\begin{abstract}
RESULTS
Healthy Infants: Data were available from 66 healthy infants (40\% boys) on 89 test occasions, [mean (SD) age: $51.2(25.0) \mathrm{w}$; length $75.4(7.5) \mathrm{cm}$; weight $9.3(2.0) \mathrm{kg}$ ]. When compared with published reference data, all FEFV outcomes derived from healthy infants tested with the current Jaeger equipment were significantly lower than predicted (Table 1).
\end{abstract}

On multilevel, univariable analysis, $\mathrm{FVC}, \mathrm{FEV}_{0.5}, \mathrm{FEV}_{75}, \mathrm{FEF}_{25-75}$ and $\mathrm{V}^{\prime}{ }_{\operatorname{maxFRC}}$ were all significantly and negatively associated with length (Table 2a) and age (Table 2b) at test. However after adjusting for length or age, addition of the other variable did not add significantly to the model, and length was chosen in preference to age to prevent any bias due to restricted growth when applying such equations to children with lung disease. Sex had already been taken into account in the original prediction equations, and was not further associated with any of the adjusted FEFV Z-scores.

After adjustment, the mean (SD) Z-scores for all FEFV outcomes in healthy controls approximated 0 (1.0), suggesting that the correction factors derived from these equations were appropriate (Table 1 and Figure 1).

\title{
Infants with CF
}

Data collected using the Jaeger equipment were available from 54 infants and young children with CF on 96 test occasions (mean (SD) age: 53.5 (26.7) w; length 73.9 (8.5) cm; weight 8.8 (2.2) kg). When results were expressed in relation to published reference equations, an abnormal $\mathrm{FEV}_{0.5}(<-$ $1.96 \mathrm{Z}$-scores) was detected on 35/85 (41\%) test occasions, whereas after applying the adjustment factor, this fell to 24 (28\%). Similar results were observed for $\mathrm{FEF}_{25-75}$ and $\mathrm{V}^{\prime}{ }_{\text {maxFRC }}$ (Table 1 and Figure 2). 


\section{DISCUSSION}

We have shown that, when using the Jaeger Masterscreen, FEFV data from healthy infants are significantly lower than published reference data, which could lead to over-diagnosis of lung disease in children with CF or other respiratory diseases. While published reference data for infant FEFV maneuvers ${ }^{9,} 10$ are clearly inappropriate for data collected using the Jaeger Masterscreen, application of an appropriate adjustment factor may minimize such errors until sufficient multicentre data are available to construct reliable equipment-specific reference ranges in this age group.

When using our original 'in-house' equipment and software (RASP), published reference data for both partial $^{9}$ and full ${ }^{10}$ FEFV maneuvers appeared to be appropriate for use in our laboratory, as demonstrated by the mean (SD) Z-scores for FEFV outcomes which approximated 0 (1) in our local healthy controls. ${ }^{6,21}$ After switching to commercial equipment (Jaeger Masterscreen BabyBody; v4.67), we used similar data collection and analysis techniques and were initially reassured that FEFV results from healthy controls appeared to remain in agreement with published reference ranges. ${ }^{5}$ However, direct comparison of a limited number of infants, using an identical jacket, suggested that flows were lower when using the Jaeger system, ${ }^{25}$ and as further healthy controls were studied using this equipment we became increasingly aware of a potential bias. ${ }^{17}$

During the validation $\operatorname{study}^{25}$ (see online supplement (OLS) for details), we established that there were no within-subject differences in pressure transmission between the systems and that the bias could not be attributed to failure to attain flow limitation, which was assessed independently for both systems by experienced operators.

Despite rigorous and time-consuming attempts to identify the source, the underlying cause of the observed discrepancies in $V^{\prime}{ }_{\text {maxFRC }}$ remains unknown. All algorithms for deriving outcomes from the Jaeger system were based on our original RASP set-up and were manually checked for 
The only major difference that we could identify between the two systems was with respect to BTPS (body temperature, pressure, saturated) corrections, ${ }^{26}$ which were applied to the flow (and hence volume) signal during data collection in the Jaeger system, whereas in our original system (and most other 'in -house' systems at the time, including those from which reference data had been generated), data were saved in original ATPS format with BTPS corrections being applied at the analysis stage. The way in which such differences could potentially impact on results is discussed in the OLS.

Equipment-specific differences in lung function have been reported previously in older subjects, ${ }^{27}$, ${ }^{28}$ and it has been suggested that such discrepancies may be due to device-dependent characteristics such as in the integration of flow to volume, which, together with BTPS corrections, may be inaccessible to the end-user. In contrast to adult spirometers, there are currently no accepted waveforms with which to compare outcome measures for infant FEFV equipment, and even if there were this would not tackle the more complex issues relating to BTPS corrections during in-vivo measurements. ${ }^{29}$ We therefore cannot ascertain whether the previous 'in-house' systems or new commercially available devices best approximate the 'truth'. What is apparent is that published reference data are not appropriate when interpreting FEFV data from the infant Jaeger equipment.

All data for this study were collected using the same version of software and in accordance with ATS/ERS recommendations ${ }^{11,12}$ by experienced investigators (AFH/SL) thereby minimizing the chance that the lower flows and volumes obtained with the new equipment were simply due to 
failure to achieve flow-limitation or poor quality control. Previous data collected from ICH using the homemade RASP system were in close agreement with that from other centers and were included in the collated dataset for $V^{\prime}{ }_{\operatorname{maxFRC}}$ prediction equations. ${ }^{9}$ Given that the mean $V_{\operatorname{maxFC}} \mathrm{Z}_{\text {- }}$ score for data collected in our laboratory using the RASP system $(n=283)$ was -0.52 , i.e. 0.88 Zscores higher than that from our recent Jaeger data, it is likely that the observed differences reflect differences in hardware and software rather than population differences or changes in practice.

This study was only possible because we retain full ethics approval to undertake lung function measurements in healthy infants and have always attempted to recruit a prospective control group for clinical research projects. In the past, many research groups prospectively recruited healthy controls, ${ }^{1,5-7,30-32}$ but during recent years there has been ongoing debate as to whether it is ethical to undertake lung function tests under sedation in healthy infants. Given the results from this study, it could be argued that it is unethical to undertake lung function tests in infants with lung disease (who are far more at risk of any sedation related adverse events than healthy children) without appropriate reference equations with which to interpret results. Indeed, had we not continued to recruit healthy controls prospectively after switching to commercially available equipment, our clinical and research data from the past 5 years would be potentially invalid. It is accepted that recruiting healthy infants to lung function studies is far more demanding and time consuming than enrolling those with lung disease, but in over 30 years of practice we have never observed an adverse event related to chloral sedation in a healthy infant, this group representing those at least risk from such events. ${ }^{33}$

The clinical implications of using inappropriate reference ranges can be seen from our results in infants with CF. The use of published reference equations would have resulted in significant overdiagnosis of abnormal lung function, and over-estimation of the rate of change in lung function during the first two years of life. Such findings are particularly pertinent at a time when there is increased emphasis on early intervention studies and the need for objective outcome measures in 
early life. ${ }^{34}$ In addition to the anxiety caused to parents, reports of apparently 'diminished' LF results in asymptomatic infants and young children could result in further potentially invasive investigations and more aggressive treatment than would be warranted if results have been underestimated, whereas errors in the reverse direction could lead to false reassurance and undertreatment.

The fact that we needed to further adjust published equations for either length or age to obtain adequate fit in healthy infants emphasizes the importance of ensuring that future reference equations are based on a large number of healthy infants with a relatively even spread over the entire age range of interest, which has not always been the case previously. Derivation of equations from datasets which include just a few individuals at the extremes, or extrapolation of predictions beyond the age or length range studied in health is particularly likely to introduce errors when interpreting results from infants with lung disease. ${ }^{35}$

Although the current study represents the largest collection of normative data using Jaeger infant equipment, given the rapid rate of growth and need for sex-specific equations, numbers are still insufficient to create reliable reference equations de novo. In addition, such equations would be based in data from a single centre which may not be applicable elsewhere. ${ }^{35}$ Consequently, until further multi-centre data can be collated, we have chosen to express the results as Z-scores using available prediction equations to adjust for sex, age and body size, before deriving an equipmentspecific adjustment factor. We will continue to collect normative data and would welcome contributions from other centers that are using the same equipment to study healthy children during the first 2 years of life. In the meantime, those using the Jaeger infant equipment are urged to interpret their data cautiously and consider applying the enclosed corrections. It must be emphasized that the correction factors presented are specific to the Jaeger equipment in our 
laboratory, and that there is an urgent need for users of other commercially available systems to undertake a similar exercise.

CONCLUSIONS AND FUTURE DIRECTIONS: The marked differences observed between FEFV data from healthy infants when collected with modern commercially available infant lung function equipment and published reference data emphasize the need for prospective recruitment of healthy controls during clinical research studies and for the development of device-specific normative data with which to interpret results from infants with lung disease. If infant lung function tests are to have any significant future role, a concerted effort from members of the ATS/ERS working group on infant and lung function tests to present the rationale and safety data to support recruitment of healthy infants for lung function tests, and discourage usage of such tests in the absence of adequate controls, is urgently needed in order to address the recent barriers introduced by the FDA and certain ethics committees. 


\section{ACKNOWLEDGEMENTS}

The authors thank the infants and their parents who participated in this study. We also thank Dr Padmaja Subbarao, Dr Amit Gupta, Ms Joanne Chittenden and Ms Alicia Bolton who provided valuable assistance in subject recruitment and performing the measurements. 


\section{REFERENCES}

1. Dezateux C, Lum S, Hoo AF, Hawdon J, Costeloe K, Stocks J. Low birth weight for gestation and airway function in infancy: exploring the fetal origins hypothesis. Thorax 2004; 59(1):6066.

2. Hoo AF, Dezateux C, Henschen M, Costeloe K, Stocks J. Development of airway function in infancy after preterm delivery. J Pediatr 2002; 141(5):652-658.

3. Young S, Arnott J, O'Keeffe PT, Le Souëf PN, Landau LI. The association between early life lung function and wheezing during the first 2 years of life. Eur Respir J 2000; 15(1):151-157.

4. Lum S, Hulskamp G, Merkus P, Baraldi E, Hofhuis W, Stocks J. Lung function tests in neonates and infants with chronic lung disease: forced expiratory maneuvers. Pediatr Pulmonol 2006; 41(3):199-214.

5. Lum S, Gustafsson P, Ljungberg $\mathrm{H}$ et al. Early detection of cystic fibrosis lung disease: multiplebreath washout versus raised volume tests. Thorax 2007; 62(4):341-347.

6. Ranganathan S, Stocks J, Dezateux C et al. The evolution of airway function in infancy and early childhood following clinical diagnosis of cystic fibrosis. Am J Respir Crit Care Med 2004; 169:928-933.

7. Friedrich L, Pitrez PM, Stein RT, Goldani M, Tepper R, Jones MH. Growth rate of lung function in healthy preterm infants. Am J Respir Crit Care Med 2007; 176(12):1269-1273.

8. Jones MH, Howard J, Davis S, Kisling J, Tepper RS. Sensitivity of spirometric measurements to detect airway obstruction in infants. Am J Respir Crit Care Med 2003; 167(9):1283-1286.

9. Hoo AF, Dezateux C, Hanrahan J, Cole TJ, Tepper R, Stocks J. Sex-specific prediction equations for $\mathrm{V}_{\operatorname{maxFRC}}$ in infancy: a multi-center collaborative study. Am J Respir Crit Care Med 2002; 165:1084-1092.

10. Jones M, Castile R, Davis S et al. Forced expiratory flows and volumes in infants. Am J Respir Crit Care Med 2000; 161:353-359.

11. ATS_ERS Consensus Statement, Lum S, Stocks J et al. Raised volume forced expirations in infants: Recommendations for current practice. Am J Respir Crit Care Med 2005; 172(11):1463-1471.

12. Sly P, Tepper R, Henschen M, Gappa M, Stocks J. Standards for infant respiratory function testing: Tidal forced expirations. Eur Respir J 2000; 16:741-748. 
19. Lum S, Hoo AF, Stocks J. Effect of airway inflation pressure on forced expiratory maneuvers from raised lung volume in infants. Pediatr Pulmonol 2002; 33(2):130-134.

20. Lum S, Hoo AF, Stocks J. Influence of jacket tightness and pressure on raised lung volume forced expiratory maneuvers in infants. Pediatr Pulmonol 2002; 34(5):361-368.

21. Lum S, Hulskamp G, Hoo AF, Ljungberg H, Stocks J. Effect of raised lung volume technique on subsequent measures of $V^{\prime}{ }_{\text {maxFRC }}$ in infants. Pediatr Pulmonol 2004; 38:146-154.

22. Alexander FE, Anderson TJ, Brown HK et al. 14 years of follow-up from the Edinburgh randomised trial of breast-cancer screening. Lancet 1999; 353(9168):1903-1908.

23. Brown HK, Prescott RJ. Applied Mixed Models in Medicine. John Wiley and sons; 1999.

24. Edwards LJ. Modern statistical techniques for the analysis of longitudinal data in biomedical research. Pediatric Pulmonology 2000; 30(4):330-344.

25. Hulskamp G, Lum S, Hoo AF et al. V'maxFRC - validation of a new commercially available equipment. European Respiratory Journal 20[Suppl 38], 224s. 2002. 
26. Bates JHT, Turner MJ, Lanteri CJ, Jonson B, Sly PD. Measurement of flow and volume. In: Stocks J, Sly PD, Tepper RS, Morgan WJ, editors. Infant Respiratory Function Testing. 1 ed. New York: John Wiley \& Sons, Inc.; 1996 p. 81-116.

27. Kunzli N, Kuna-Dibbert B, Keidel D et al. Longitudinal validity of spirometers--a challenge in longitudinal studies. Swiss Med Wkly 2005; 135(33-34):503-508.

28. Orfei L, Strachan DP, Rudnicka AR, Wadsworth ME. Early influences on adult lung function in two national British cohorts. Arch Dis Child 2008; 93(7):570-574.

29. Broughton SJ, Sylvester KP, Page CM, Rafferty GF, Milner AD, Greenough A. Problems in the measurement of functional residual capacity. Physiol Meas 2006; 27(2):99-107.

30. Castile RG, Iram D, McCoy KS. Gas trapping in normal infants and in infants with cystic fibrosis. Pediatr Pulmonol 2004; 37(5):461-469.

31. Linnane BM, Hall GL, Nolan G et al. Lung function in infants with cystic fibrosis diagnosed by newborn screening. Am J Respir Crit Care Med 2008; 178(12):1238-1244.

32. Tepper RS, Williams-Nkomo T, Martinez T, Kisling J, Coates C, Daggy J. Parental smoking and airway reactivity in healthy infants. Am J Respir Crit Care Med 2005; 171(1):78-82.

33. Gaultier C, Fletcher ME, Beardsmore C, England S, Motoyama E. Respiratory function measurements in infants: measurement conditions. Working Group of the European Respiratory Society and the American Thoracic Society. Eur Respir J 1995; 8(6):1057-1066.

34. Davis SD, Ratjen F. Reduced lung function in cystic fibrosis: a primary or secondary phenotype? Am J Respir Crit Care Med 2008; 178(1):2-3.

35. Stanojevic S, Wade A, Stocks J. Reference values for lung function: past, present and future. Eur Respir J. In press. 


\section{FIGURE LEGENDS}

Figure 1: FEFV data from healthy infants expressed as Z-scores plotted against length at test, A) according to published reference equations $\left(\mathrm{FEV}_{0.5}, \mathrm{FEF}_{25-75}\right.$ using Jones et al, ${ }^{10}$ and $\mathrm{V}_{\text {maxFR }}$ according to $\mathrm{Hoo}$ et $\mathrm{al}^{9}$ and $\mathrm{B}$ ) after adjusting for the Jaeger equipment used. Open circles represent girls and closed circles are boys.

The Upper and Lower Limit of the Normal range (ULN and LLN, as defined by \pm 1.96 Z-scores) are shown. Data from only one test occasion per child are shown on these graphs.

Figure 2: Comparison of FEFV data from healthy infants (HC) and those with CF; A) before and B) after adjustment for equipment.

The solid lines denote the mean value for the group and the Upper and Lower Limit of the Normal range (ULN and LLN, as defined by \pm 1.96 Z-scores) are shown. Data from only one test occasion per child are shown on these graphs.

Reliance on published reference would have resulted in $17 \mathrm{CF}$ infants and $9 \mathrm{HC}$ being classified as having 'abnormal' $\mathrm{FEV}_{0.5}(<-1.96 \mathrm{Z}$-scores). After adjusting for equipment, 41\% (7/17) of $\mathrm{CF}$ infants with 'abnormal' results were shown to have been mis-classified. Similarly for forced expiratory flows, $20(45 \%)$ and $25(49 \%) \mathrm{CF}$ infants were identified as having diminished $\mathrm{FEF}_{25-75}$ and $V^{\prime}$ maxFRC, respectively, when using the unadjusted published references, of which $65 \%(13 / 20)$ and $80 \%(20 / 25)$ would have been mis-classified. 
Table 1: Comparison of FEFV data between healthy infants and those with CF, before and after adjusting the prediction equations.

\begin{tabular}{|c|c|c|c|c|c|c|}
\hline & \multicolumn{3}{|c|}{ Published reference } & \multicolumn{3}{|c|}{ Adjusted for equipment } \\
\hline & & & Mean $(95 \% \mathrm{CI})$ difference & & & Mean (95\% CI) adjusted \\
\hline & $\mathrm{CF}$ & Control & (CF-Control) & $\mathrm{CF}$ & Control & difference (CF-Control) \\
\hline $\mathrm{n}$ & 96 & $87^{d}$ & & 96 & $87^{\mathrm{e}}$ & \\
\hline $\mathrm{FVC}^{\mathrm{a}}$ & $-1.27(1.16)^{c}$ & $-0.38(1.11) *$ & $-0.89(-1.24 ;-0.54)^{* * *}$ & $-0.97(1.18)^{c}$ & $0.02(1.14)$ & $-1.00(-1.34 ;-0.66)^{* * *}$ \\
\hline $\mathrm{FEV}_{0.5}^{\mathrm{a}}$ & $-1.65(1.42)^{\mathrm{c}}$ & $-0.58(0.99)^{* * *}$ & $-1.06(-1.43 ;-0.69)^{* * *}$ & $-1.18(1.35)^{c}$ & $-0.03(0.90)$ & $-1.15(-1.50 ;-0.80)^{* * *}$ \\
\hline $\mathrm{FEF}_{25-75}{ }^{\mathrm{a}}$ & $-1.77(1.56)^{c}$ & $-0.98(1.04)^{* * *}$ & $-0.79(-1.20 ;-0.38)^{* * *}$ & $-0.76(1.52)^{c}$ & $0.10(1.00)$ & $-0.86(-1.25 ;-0.46)^{* * *}$ \\
\hline$V_{\operatorname{maxFRC}}^{\prime}$ & $-1.65(1.24)$ & $-1.41(1.08)^{* * *}$ & $-0.25(-0.59 ; 0.09)$ & $-0.37(1.17)$ & $0.00(0.92)$ & $-0.38(-0.68 ;-0.07)^{*}$ \\
\hline
\end{tabular}

Data expressed as Mean (SD) Z-scores; * $\mathrm{p}<0.05 ; * * *: \mathrm{p}<0.001$

${ }^{\text {a Jones }} 2000$ AJRCCM, with smoking during pregnancy status set to $0 .{ }^{10}$

${ }^{\text {b}}$ Hoo 2002 AJRCCM. ${ }^{9}$

c $\mathrm{n}=85$;

d significance of difference based on comparison of Z-score results from healthy controls and that predicted from published reference equations (i.e mean (SD) of 0 (1). 


\section{Page 19 of 50}

Lung function in healthy infants

Lum et al

By definition, one would expect $95 \%$ of a healthy population to fall within \pm 1.96 SD or Z-scores of predicted values. ${ }^{15,32}$ Before adjustment (d), all FEFV outcomes from healthy controls were significantly lower than predicted from published reference values; whereas after adjustment (e), the mean (SD) for all results approximated 0 (1). When compared with controls, $\mathrm{FVC}, \mathrm{FEV}_{0.5}$ and $\mathrm{FEF}_{25-75}$ were significantly lower in infants with $\mathrm{CF}$, both before and after adjustment. Although the magnitude of group differences were slightly greater after adjustment, the number of individual infants with CF who were classified with abnormal lung function (<1.96 Z-scores) was lower (see Fig 2). 
Table 2a: Adjusted prediction equations taking length into account (Jaeger Z-scores)

\begin{tabular}{ll}
\hline Adjusted zFVC & $=\mathrm{zFVC}_{(\text {Jones })}+(0.057 \times$ length, $\mathrm{cm})-3.90$ \\
Adjusted $\mathrm{zFEV}_{0.5}$ & $=\mathrm{zFEV}_{0.5(\text { Jones })}+(0.058 \times$ length, $\mathrm{cm})-3.83$ \\
Adjusted $\mathrm{zFEF}_{75}$ & $=\mathrm{zFEF}_{75 \text { (Jones) }}+(0.037 \times$ length, $\mathrm{cm})-1.94$ \\
Adjusted $\mathrm{zFEF}_{25-75}$ & $=\mathrm{zFEF}_{25-75(\text { Jones })}+(0.040 \times$ length, $\mathrm{cm})-1.94$ \\
Adjusted $\mathrm{V}_{\text {maxFRC }}$ & $=\mathrm{z} V_{\text {maxFRC (Hoo) }}^{\prime}+(0.074 \times$ length, $\mathrm{cm})-4.17$
\end{tabular}

Table 2b: Adjusted prediction equations taking age into account

\begin{tabular}{|c|c|}
\hline Adjusted zFVC & $=\mathrm{zFVC}_{(\text {Jones })}+(0.018 *$ age, weeks $)-0.538$ \\
\hline Adjusted zFEV 0.5 & $=\mathrm{zFEV}_{0.5(\text { Jones })}+(0.018 *$ age, weeks $)-0.341$ \\
\hline Adjusted $\mathrm{zFEF}_{75}$ & $=\mathrm{zFEF}_{75 \text { (Jones) }}+(0.010 *$ age, weeks $)-0.347$ \\
\hline Adjusted zFEF $25-75$ & $=\mathrm{zFEF}_{25-75 \text { (Jones) }}+(0.011 *$ age, weeks $)-0.491$ \\
\hline Adjusted $V^{\prime}{ }_{\max F R C}$ & $=\mathrm{z} V_{\operatorname{maxFRC}(\mathrm{Hoo})}^{\prime}+(0.020 *$ age, weeks $)-0.355$ \\
\hline
\end{tabular}

Age and length contributed equally and significantly to these models. After adjusting for length or age, addition of the other variable did not add significantly to the model, and length was chosen in preference to age to prevent any bias due to restricted growth when applying such equations to children with lung disease. 
Fig 1
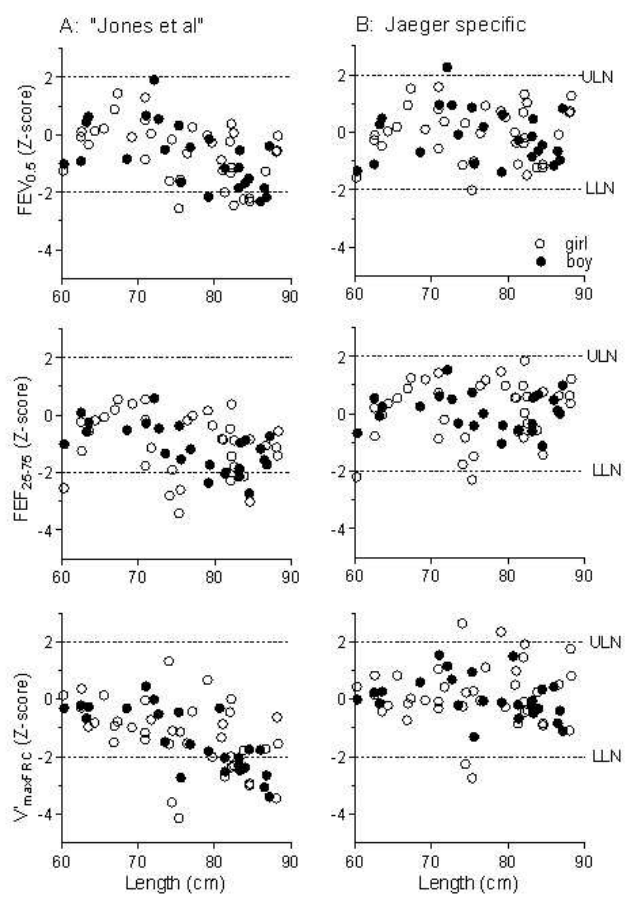

Figure 1: FEFV data from healthy infants expressed as Z-scores plotted against length at test, A) according to published reference equations ( $\mathrm{FEV}_{0.5}, \mathrm{FEF}_{25-75}$ using Jones et al, ${ }^{10}$ and $\mathrm{V}_{\text {maxFRC }}$ according to $\mathrm{HoO}$ et $\mathrm{al}^{9}$ and $\mathrm{B}$ ) after adjusting for the Jaeger equipment used. Open circles represent girls and closed circles are boys.

The Upper and Lower Limit of the Normal range (ULN and LLN, as defined by \pm 1.96 Z-scores) are shown. Data from only one test occasion per child are shown on these graphs.

$254 \times 190 \mathrm{~mm}(96 \times 96 \mathrm{DPI})$

John Wiley \& Sons, Inc. 


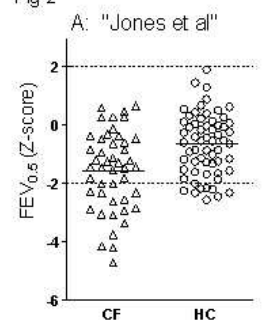

B: Jaeger specific

Figure 2: Comparison of FEFV data from healthy infants ( $\mathrm{HC}$ ) and those with $\mathrm{CF} ; \mathrm{A}$ ) before and $\mathrm{B}$ ) after adjustment for equipment.

The solid lines denote the mean value for the group and the Upper and Lower Limit of the Normal range (ULN and LLN, as defined by \pm 1.96 Z-scores) are shown. Data from only one test occasion per child are shown on these graphs.

Reliance on published reference would have resulted in $17 \mathrm{CF}$ infants and $9 \mathrm{HC}$ being classified as having 'abnormal' $\mathrm{FEV}_{0.5}$ (<-1.96 Z-scores). After adjusting for equipment, $41 \%$ (7/17) of CF infants with 'abnormal' results were shown to have been mis-classified. Similarly for forced expiratory flows, $20(45 \%)$ and $25(49 \%)$ CF infants were identified as having diminished $\mathrm{FEF}_{25-75}$ and $\mathrm{V}_{\text {maxFRC, }}^{\prime}$ respectively, when using the unadjusted published references, of which $65 \%(13 / 20)$ and $80 \%(20 / 25)$ would have been mis-classified. $254 \times 190 \mathrm{~mm}(96 \times 96$ DPI) 
Lung function in healthy infants_OLS

POTENTIAL MISINTERPRETATION OF INFANT LUNG FUNCTION UNLESS PROSPECTIVE HEALTHY CONTROLS ARE STUDIED

Sooky Lum, $\mathrm{PhD}^{1}$; Ah-Fong Hoo, $\mathrm{PhD}^{1,2}$; Georg Hulskamp, $\mathrm{MD}^{3}$; Angie Wade, $\mathrm{PhD}^{4}$ and Janet Stocks, $\mathrm{PhD}^{1}$

On-line supplement 
Lung function in healthy infants_OLS

\title{
ADDITIONAL DATA
}

The following details described a small validation study presented at the European Respiratory Society conference, 2002 . $^{\mathrm{E}-1}$

\begin{abstract}
V' ${ }_{\text {maxFRC }}$ - Validation of a new commercially available equipment Background:

Measurements of maximal flow at functional residual capacity ( $\mathrm{V}_{\text {maxFRC }}$ ) using the tidal rapid thoraco-abdominal compression technique (RTC) are the most popular method for assessing small airway function in infants and young children.
\end{abstract}

Sex specific prediction equations for $V^{\prime}$ maxFRC have been published recently ${ }^{\mathrm{E}-2}$ which should improve interpretation of results.

However, it is not yet known whether these equations will be appropriate for use with data collected using new commercially available equipment such as the Jaeger MasterScreen infant lung function system (Lab4 software version 4.53, Jaeger Toennies, Viasys Healthcare)

Aim:

To investigate whether published $\mathrm{z}$ scores for $\mathrm{V}^{\prime}{ }_{\operatorname{maxFR}}$ during infancy are appropriate for data collected with the Jaeger system by

- validating algorithms used by the Jaeger system against the established 'Squeeze' software [Version 2.04, Imperial College, London, 1999].

- comparing paired measurements of $\mathrm{V}^{\prime}$ maxFRC using the Jaeger $(\mathrm{J})$ and the previously validated RASP-Squeeze (RS) system on the same occasion.

Subjects and methods:

$\mathrm{V}_{\text {maxFRC }}^{\prime}$ was measured using ERS/ATS recommendations ${ }^{\mathrm{E}-3}$ on 17 occasions in 12 healthy babies recruited to ongoing epidemiological studies (range for weight: $3.6-11.1 \mathrm{~kg}$; length: 53

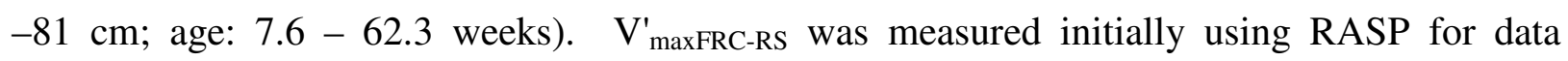


Lung function in healthy infants_OLS

collection and 'Squeeze" software for data analysis. $\mathrm{V}_{\text {maxFRC-J }}$ was obtained immediately afterwards within the same sleep epoch (delay $<10 \mathrm{~min}$ ), using the same jacket. The mean of the 3 highest, technically acceptable manoeuvers from each system were compared. Data from $10 \mathrm{~V}_{\text {maxFRC-J }}^{\prime}$ trials, that had been simultaneously recorded as ASCII files, were imported into the 'Squeeze' software for re-analysis and results compared to those calculated by Jaeger.

Results:

1) Comparison of Algorithms:

As summarised in E-Table 1 and E-Figure 1, there were no differences in any of the measured parameters on reanalysis of Jaeger data, with the exception of $\mathrm{V}_{\text {maxFRC-J }}^{\prime}$ which was on average 5\% higher (95\% CI: 3.4; 7.0\%) when calculated automatically. This was due to minor differences in method of calculating the end expiratory level.

E-Table 1: Comparison of algorithms: Jaeger vs Squeeze

Mean difference $(95 \% \mathrm{CI})$

\begin{tabular}{llll} 
& Jaeger & 'Squeeze' & [Jaeger-'Squeeze'] \\
\cline { 2 - 4 } $\mathrm{V}_{\operatorname{maxFRC}}^{\prime}\left(\mathrm{ml} . \mathrm{s}^{-1}\right)$ & $244(53)$ & $231(45)$ & $13(6,19) *$
\end{tabular}

Jacket pressure $(\mathrm{kPa}) \quad 7.7(0.8) \quad 7.7(0.8)$

0

$\mathrm{V}_{\mathrm{T}}(\mathrm{ml})$

$90.6(14.8)$

$90.3(14.6)$

$0.2(-0.4,0.7)$

$\operatorname{PEF}\left(\mathrm{ml} . \mathrm{s}^{-1}\right)$

476 (39)

$476(40)$

$0.4(-0.4,1.3)$

Data as mean (SD), *p $<0.05$ 
Lung function in healthy infants_OLS

E-Figure 1: Comparison of $\mathrm{V}_{\text {maxFRC-s }}^{\prime}$ with identical raw data recalculated by the 'Squeeze' program.

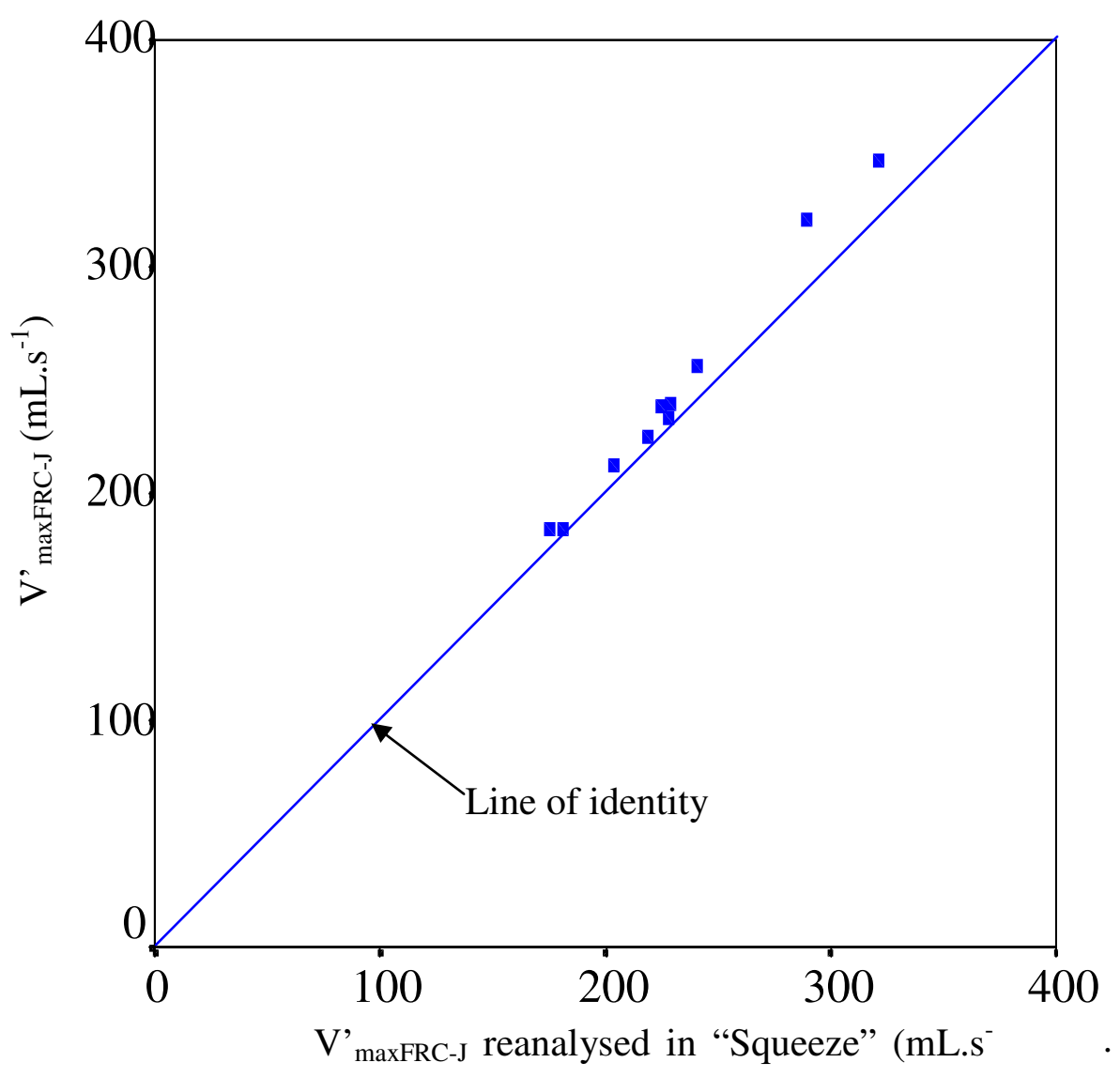

2) In vivo comparisons:

There were no significant differences in jacket pressure or breathing pattern between the 2 sets of measurements, although there was a tendency for $\mathrm{V}_{\mathrm{T}}$ to be slightly higher in Jaeger $(\mathrm{p}=0.08$;

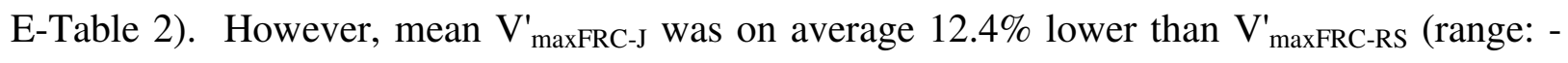
$37 \%,+26 \%$ ) (E-Figure 2). The mean (range) difference in $\mathrm{z}$ scores (J-RS) was - 0.35 (- 0.98 to 0.28) $(\mathrm{p}<0.001)$. 
Lung function in healthy infants_OLS

E-Table 2: In vivo comparison: Jaeger vs RASP

\begin{tabular}{cccc}
\hline & & & Mean difference (95\% CI) \\
& Jaeger & RASP & [Jaeger-RASP] \\
\cline { 2 - 4 } $\mathrm{V}_{\text {maxFRC }\left(\mathrm{ml}^{\prime} \mathrm{s}^{-1}\right)}$ & $154(91)$ & $180(99)$ & $-26(-37,-15) *$ \\
Jacket pressure $(\mathrm{kPa})$ & $6.4(1.7)$ & $6.2(1.4)$ & $0.2(-0.3,0.6)$ \\
$\mathrm{V}_{\mathrm{T}}(\mathrm{ml})$ & $75.5(18.5)$ & $71.7(18.8)$ & $3.8(-0.3,8)$ \\
$\mathrm{PEF}\left(\mathrm{ml} . \mathrm{s}^{-1}\right)$ & $402(102)$ & $402(116)$ & $-0.8(-21,20)$ \\
\hline Data as mean $(\mathrm{SD}),{ }^{*} \mathrm{p}<0.05$ & &
\end{tabular}

E-Figure 2: Within subject comparisons using Jaeger and RASP

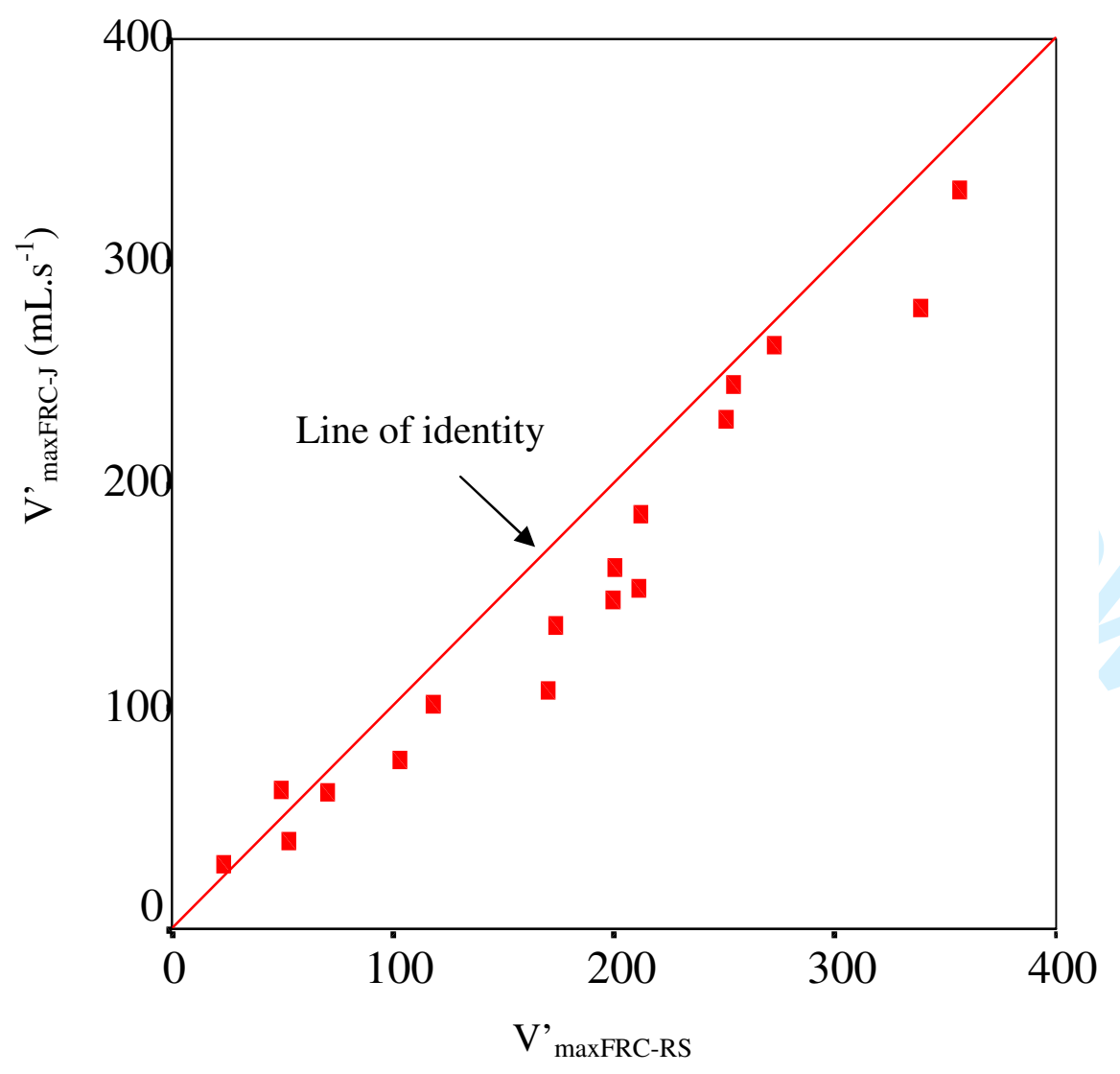


Lung function in healthy infants_OLS

Discussion:

This study suggests that values of $V^{\prime}$ maxFRC are somewhat lower when measured using the Jaeger MasterScreen than our previously published data. Sex specific prediction equations for $\mathrm{V}_{\max }^{\prime}{ }_{\mathrm{m} C}$ have been published recently ${ }^{\mathrm{E}-1}$ which should improve interpretation of results.

These discrepancies are NOT due to:

- differences in algorithms (Jaeger giving if anything slightly higher values)

- differences in jacket design or pressure transmission (identical for paired data collected using both systems)

- failure to reach flow limitation (this was assessed independently for both systems)

- differences in apparatus deadspace (14.1 vs $16.8 \mathrm{~mL}$ including $10 \mathrm{~mL}$ for mask deadspace for Jaeger and RASP

The observed discrepancies could, however, be due to the timing of assessments, since RASP was always assessed first as the "gold standard" for ongoing epidemiological studies, repeat measures with Jaeger only being performed in those who remained in quiet sleep. Repeated thoracoabdominal compression using pressures high enough to reach flow limitation may result in changes in lung and airway mechanics, including $\mathrm{V}^{\prime}$ maxFRC.

Conclusion:

Validation of infant lung function equipment is notoriously difficult, not least because of limited duration of sleep and ethical restraints which generally preclude recruitment into a purely methodological study. Before Jaeger results can confidently be expressed in terms of published $\mathrm{z}$-scores for $\mathrm{V}_{\operatorname{maxFRC}}^{\prime}$ further work will be required to investigate the cause of observed discrepancies, including comparisons wherein measurements with the Jaeger system precede those with RASP. 
Lung function in healthy infants_OLS

\section{BTPS correction}

Failure to apply BTPS correction during data correction will lead to a downward drift of tidal volume against time (expired volume being greater than inspired volume) whereas overcorrection of inspiratory flow for BTPS conditions will lead to an upward drift of tidal volume. While both scenarios can be adjusted by using a timed-based volume drift correction (as commonly employed in all lung function software, whether 'in house' or commercial), this is generally only applied to the volume signal and could thus alter the shape of the Flow- Volume curve and hence measured values of both forced expired flows and volumes.

While BTPS corrections have traditionally been applied in adult lung function systems to correct for the warming of inspired air and cooling of expired air during the breathing cycle, direct instantaneous measures of temperature change at the mouth during the breathing cycle in adults have indicated that some warming occurs through the equipment before the air passes through the pneumotach on inspiration, with some cooling on expiration. Consequently, Jaeger apply an $8 \%$ inspiratory and $3 \%$ expiratory correction to all flows in their 'adult and pediatric' systems, which generally results in a fairly stable tidal volume-time trace, Since such measurements have not been undertaken in infants due to their complexity, the Jaeger infant lung function system simply applies the theoretical $11 \%$ correction to inspired flows with no expiratory correction, ${ }^{\mathrm{E}-4}$ which tends to result in some upward drift of tidal volume which is subsequently adjusted for during screen display using a volume-time drift correction. By contrast, in our original 'in-house' system we did not apply any BTPS correction during data collection, instead correcting the data to BTPS where appropriate at time of analysis, such that the tidal volume time-based tended to drift downwards, the drift correction being in the reverse direction. The 'truth' probably lies somewhere between these two approaches, the ideal situation being one in which accurate BTPS corrections are applied on a breath by breath basis; a 
Lung function in healthy infants_OLS

scenario yet to be realized in any adult lung function software for adults, let alone the more complex situation faced when testing infants.

\section{References}

E-1. Hulskamp G, Lum S, Hoo AF et al. V'maxFRC - validation of a new commercially available equipment. European Respiratory Journal 20[Suppl 38], 224s. 2002.

E-2. Hoo AF, Dezateux C, Hanrahan J, Cole TJ, Tepper R, Stocks J. Sex-specific prediction equations for $\mathrm{V}_{\text {maxFRC }}$ in infancy: a multi-center collaborative study. Am J Respir Crit Care Med 2002; 165:1084-1092.

E-3. Sly P, Tepper R, Henschen M, Gappa M, Stocks J. Standards for infant respiratory function testing: Tidal forced expirations. Eur Respir J 2000; 16:741-748.

E-4. Bates JHT, Turner MJ, Lanteri CJ, Jonson B, Sly PD. Measurement of flow and volume. In: Stocks J, Sly PD, Tepper RS, Morgan WJ, editors. Infant Respiratory Function Testing. 1 ed. New York: John Wiley \& Sons, Inc.; 1996 p. 81-116. 


\section{POTENTIAL MISINTERPRETATION OF INFANT LUNG FUNCTION UNLESS PROSPECTIVE HEALTHY CONTROLS ARE STUDIED}

Sooky Lum, PhD ${ }^{1}$; Ah-Fong Hoo, PhD ${ }^{1,2}$; Georg Hulskamp, $\mathrm{MD}^{3}$; Angie Wade, PhD ${ }^{4}$ and Janet Stocks, PhD ${ }^{1}$

${ }^{1}$ Portex Unit: Respiratory Physiology and Medicine, UCL, Institute of Child Health, London, ${ }^{2}$ Great Ormond Street Hospital for Children NHS Trust, London, ${ }^{3}$ Department of Paediatrics, Universitätsklinikum and Clemenshospital, Münster, Germany and ${ }^{4}$ Centre for Paediatric Epidemiology and Biostatistics Unit, London, UK.

Funding source: Medical Research Council, UK; Cystic Fibrosis Trust; British Lung Foundation. Research at the Institute of Child Health and Great Ormond Street Hospital for Children NHS Trust benefits from R\&D funding received from the NHS Executive.

Corresponding author: Sooky Lum

Portex Respiratory Unit

UCL, Institute of Child Health

30 Guilford Street

London WC1N 1EH

Email: $\underline{\text { s.lum@ich.ucl.ac.uk }}$

Tel: +44 (0)20 $79052382 \quad$ Fax: +44 (0)20 78298634

Reprints are not available from the authors.

Abbreviated title: Lung function in healthy infants

This article has an online data supplement. 


\section{SUMMARY}

Rationale: Reliable interpretation of pulmonary function tests relies on appropriate reference data which remain very limited for infants.

Objectives: This study aimed to assess the validity of published reference equations for forced expiratory flow-volume (FEFV) data in infants when using current, commercially available equipment, and how this could impact on interpretation of results from infants with lung disease.

Methods: The Jaeger Masterscreen BabyBody (v4.67) equipment was used to perform partial and raised volume FEFV maneuvers in healthy infants and those with cystic fibrosis $(\mathrm{CF})$. Results were initially expressed as Z-scores using published reference equations. Multilevel modelling was used to calculate differences, if any, from predicted scores in healthy infants.

Results: Data were available from 66 healthy fullterm infants on 89 test occasions; [median (range) postnatal age 49.4(12-101) weeks. All FEFV outcomes were significantly lower than predicted, with mean (SD) Z-score differences of -0.4(1.1) for $\mathrm{FVC}$; -0.6(1.0) for $\mathrm{FEV}_{0.5}$; -1.0(1.0) for $\mathrm{FEF}_{25-75}$ and -1.4(1.1) for $\mathrm{V}^{\prime}{ }_{\text {maxFRC. }}$ After adjustments using multilevel modelling, mean Z-scores were within $0.1(\mathrm{SD} 1.0)$ predicted for all outcomes in healthy infants. Among 50 infants with CF, studied on 85 test occasions, results were 'abnormal' (<-1.96 Z-scores) on $35(41 \%)$ and $37(45 \%)$ test occasions for $\mathrm{FEV}_{0.5}$ and $\mathrm{FEF}_{25-75}$ respectively when using published equations. This fell to $24(28 \%)$ and $20(24 \%)$ respectively, after adjustment.

Conclusions: Dependence on published equations for interpreting FEFV data in infants may lead to misinterpretation of lung function status, which could impact adversely both in the research setting and on clinical management. Use of a contemporary control group or establishment of equipmentspecific reference data is essential for meaningful interpretation of infant lung function data.

Keywords: Infant; forced expiratory maneuvers; pulmonary function test; Reference values; equipment 


\section{INTRODUCTION}

Assessments of forced expiration have been used extensively in older children and adults to assess the nature and severity of airway disease, response to therapeutic intervention and to monitor disease progression or resolution in both the clinical and research environments. While infants cannot be instructed to perform such maneuvers, forced expiratory flow-volume (FEFV) loops can be obtained by substituting voluntary effort with externally applied pressure to the chest and abdomen to force expiration. Measurements of maximal flow at functional residual capacity $\left(V_{\operatorname{maxFRC}}\right)$ from the tidal rapid thoraco-compression technique (RTC) have been used to characterize growth and development of the airways during infancy ${ }^{1-3}$ and, together with data derived from the raised volume RTC (RVRTC), have been found to discriminate clearly between health and disease within the research setting. ${ }^{4-8}$ Nevertheless, if such tests are to be used in clinical management, reliable reference ranges are also required.

While prediction equations have been published for infant FEFV outcomes, 9,10 these were derived from children studied using equipment developed 'in-house' and the extent to which they remain appropriate for current, commercially available equipment that was introduced following recommendations from the ATS-ERS task force on infant lung function ${ }^{11-13}$ has yet to be determined. The need to assess whether selected prediction equations are appropriate for a given population or specific equipment is well-recognized, ${ }^{14-16}$ but has rarely been done in infants due to the time-consuming nature of these tests and need for sedation. In addition, increasing difficulty in obtaining ethics committee approval for sedating healthy infants during the past decade has severely limited the extent to which normal growth and development of infant lung function can be assessed in several countries, including the USA.

The aims of this study were to: a) assess whether FEFV results obtained from healthy infants using the current Jaeger equipment differ from predicted values, b) investigate whether, in the event of any significant offset, it would be possible to adjust for any equipment-specific differences in order 
to facilitate interpretation in infants with lung disease and c) evaluate the impact of applying such a correction factor to a cohort of infants with cystic fibrosis (CF) studied using identical equipment and techniques. Some of the results included in this study have been reported previously. ${ }^{5,17}$ 


\section{MATERIALS AND METHODS}

The study population was comprised of:

a) healthy fullterm (>37 gestational weeks) white infants without congenital abnormalities or respiratory compromise (i.e. no current respiratory problems or history of respiratory illness requiring hospitalization) who had been recruited to epidemiological studies or as controls for clinical research $^{5,17,18}$ and

b) Infants diagnosed with CF without severe congenital, cardiovascular or neuromuscular disorders that could impact on the respiratory system, who had been recruited to clinical research studies. ${ }^{5}$ Children with a history of apneic episodes or upper airway pathology were excluded. Local Research Ethics Committee approval was granted and written informed parental consent was obtained for all infants.

Equipment and study protocol: With the exception of two infants with CF who had had repeated respiratory exacerbations and were therefore tested as soon as asymptomatic for 14 days, lung function tests in all children were undertaken at least 3 weeks after any respiratory illness. Data were collected during quiet sleep, after oral sedation with chloral hydrate $(50-100 \mathrm{mg} / \mathrm{kg}$ depending on age). RTC and RVRTC data were collected using the Jaeger Masterscreen BabyBody System (CareFusion, San Diego). This equipment was designed in adherence with the ATS-ERS recommendations ${ }^{11-13}$ and uses a low deadspace pneumotachometer with solid-state transducers. Tidal and raised volume maneuvers were performed in accordance with international recommendations ${ }^{11,12}$ as previously described, ${ }^{19,}{ }^{20}$ with the tidal RTC being performed prior to raised volume maneuvers. ${ }^{21}$ The RVRTC was performed from an inflation pressure of $30 \mathrm{cmH}_{2} \mathrm{O}$, the maneuver being repeated until a minimum of three acceptable and reproducible FEFV curves was obtained. Forced expiratory volume in 0.5 second $\left(\mathrm{FEV}_{0.5}\right)$, forced vital capacity (FVC), forced expiratory flow when $75 \% \mathrm{FVC}$ had been expired $\left(\mathrm{FEF}_{75}\right)$ and $\mathrm{FEF}$ between $25-75 \% \mathrm{FVC}\left(\mathrm{FEF}_{25}\right.$ 75) were reported from the "best" raised volume curve. The latter was defined as the technically 
acceptable forced expiratory FEFV curve with the highest sum of FVC and FEV ${ }_{0.5}{ }^{11}$ For RTC, the mean $V_{\text {maxFR }}^{\prime}$ from at least two (usually three) reproducible FEFV curves was reported. ${ }^{12}$

\section{Statistical Analysis}

Power calculations demonstrated that FEFV measurements from 65 healthy children would enable differences equivalent to $0.4 \mathrm{SD}$ (or Z-scores) to be detected between the controls and the published reference population with $90 \%$ power at the 0.05 significance level. Standard software packages were used for data inspection, distribution and descriptive statistics (SPSS for Windows, v15.0, SPSS Inc.). Results from healthy controls were expressed as Z-scores using published prediction equations. ${ }^{9,10}$ To ensure that we would still be able to detect differences between those exposed to maternal smoking during pregnancy compared to those who were not, the calculation of Z-scores for RVRTC data was made with smoking status during pregnancy being set to 0 (zero) . The extent to which these Z-scores differed from zero according to sex, age and body size was inspected and univariable regression analysis was used to establish the association between each FEFV outcome and likely explanatory variables. Where potentially significant associations existed, these were further explored using multivariable, multilevel regression modeling (MLwiN, version 2.12; Institute of Education, UK). These highly flexible models adjust for the correlated nature of repeated measurements in individuals and allow inclusion of variable numbers of measurements per child to provide the most precise characterization of changes over time. ${ }^{22-24}$ To quantify the extent to which age or length was independently associated, after adjusting for factors accounted for by the Jones and Hoo equations ${ }^{9,10}$, a stepwise approach was used in developing the multivariable models: each dependent (FVC, $\mathrm{FEV}_{0.5}$ etc) was adjusted for potential determinants such as length, age, sex etc. The derived regression equations for the LF variables were then applied to results from children with CF to evaluate the potential impact of applying such an adjustment factor on clinical management. Data management was undertaken using Re-Base software (J7IS Ltd). 


\begin{abstract}
RESULTS
Healthy Infants: Data were available from 66 healthy infants (40\% boys) on 89 test occasions, [mean (SD) age: $51.2(25.0)$ w; length $75.4(7.5) \mathrm{cm}$; weight 9.3 (2.0) kg]. When compared with published reference data, all FEFV outcomes derived from healthy infants tested with the current Jaeger equipment were significantly lower than predicted (Table 1).
\end{abstract}

On multilevel, univariable analysis, $\mathrm{FVC}, \mathrm{FEV}_{0.5}, \mathrm{FEV}_{75}, \mathrm{FEF}_{25-75}$ and $\mathrm{V}$ 'maxFR were all significantly and negatively associated with length (Table 2a) and age (Table 2b) at test. However after adjusting for length or age, addition of the other variable did not add significantly to the model, and length was chosen in preference to age to prevent any bias due to restricted growth when applying such equations to children with lung disease. Sex had already been taken into account in the original prediction equations, and was not further associated with any of the adjusted FEFV Z-scores.

After adjustment, the mean (SD) Z-scores for all FEFV outcomes in healthy controls approximated 0 (1.0), suggesting that the correction factors derived from these equations were appropriate (Table 1 and Figure 1).

\title{
Infants with CF
}

Data collected using the Jaeger equipment were available from 54 infants and young children with CF on 96 test occasions (mean (SD) age: 53.5 (26.7) w; length 73.9 (8.5) cm; weight 8.8 (2.2) kg). When results were expressed in relation to published reference equations, an abnormal $\mathrm{FEV}_{0.5}(<-$ $1.96 \mathrm{Z}$-scores) was detected on 35/85 (41\%) test occasions, whereas after applying the adjustment factor, this fell to 24 (28\%). Similar results were observed for $\mathrm{FEF}_{25-75}$ and $\mathrm{V}^{\prime}{ }_{\text {maxFRC }}$ (Table 1 and Figure 2). 


\section{DISCUSSION}

We have shown that, when using the Jaeger Masterscreen, FEFV data from healthy infants are significantly lower than published reference data, which could lead to over-diagnosis of lung disease in children with CF or other respiratory diseases. While published reference data for infant FEFV maneuvers ${ }^{9,10}$ are clearly inappropriate for data collected using the Jaeger Masterscreen, application of an appropriate adjustment factor may minimize such errors until sufficient multicentre data are available to construct reliable equipment-specific reference ranges in this age group.

When using our original 'in-house' equipment and software (RASP), published reference data for both partial $^{9}$ and full ${ }^{10}$ FEFV maneuvers appeared to be appropriate for use in our laboratory, as demonstrated by the mean (SD) Z-scores for FEFV outcomes which approximated 0 (1) in our local healthy controls. ${ }^{6,21}$ After switching to commercial equipment (Jaeger Masterscreen BabyBody; v4.67), we used similar data collection and analysis techniques and were initially reassured that FEFV results from healthy controls appeared to remain in agreement with published reference ranges. ${ }^{5}$ However, direct comparison of a limited number of infants, using an identical jacket, suggested that flows were lower when using the Jaeger system, ${ }^{25}$ and as further healthy controls were studied using this equipment we became increasingly aware of a potential bias. ${ }^{17}$

During the validation $\operatorname{study}^{25}$ (see online supplement (OLS) for details), we established that there were no within-subject differences in pressure transmission between the systems and that the bias could not be attributed to failure to attain flow limitation, which was assessed independently for both systems by experienced operators.

Despite rigorous and time-consuming attempts to identify the source, the underlying cause of the observed discrepancies in $V^{\prime}{ }_{\text {maxFRC }}$ remains unknown. All algorithms for deriving outcomes from the Jaeger system were based on our original RASP set-up and were manually checked for 
The only major difference that we could identify between the two systems was with respect to BTPS (body temperature, pressure, saturated) corrections, ${ }^{26}$ which were applied to the flow (and hence volume) signal during data collection in the Jaeger system, whereas in our original system (and most other 'in -house' systems at the time, including those from which reference data had been generated), data were saved in original ATPS format with BTPS corrections being applied at the analysis stage. The way in which such differences could potentially impact on results is discussed in the OLS.

Equipment-specific differences in lung function have been reported previously in older subjects, ${ }^{27}$, ${ }^{28}$ and it has been suggested that such discrepancies may be due to device-dependent characteristics such as in the integration of flow to volume, which, together with BTPS corrections, may be inaccessible to the end-user. In contrast to adult spirometers, there are currently no accepted waveforms with which to compare outcome measures for infant FEFV equipment, and even if there were this would not tackle the more complex issues relating to BTPS corrections during in-vivo measurements. ${ }^{29}$ We therefore cannot ascertain whether the previous 'in-house' systems or new commercially available devices best approximate the 'truth'. What is apparent is that published reference data are not appropriate when interpreting FEFV data from the infant Jaeger equipment.

All data for this study were collected using the same version of software and in accordance with ATS/ERS recommendations ${ }^{11,12}$ by experienced investigators (AFH/SL) thereby minimizing the chance that the lower flows and volumes obtained with the new equipment were simply due to 
failure to achieve flow-limitation or poor quality control. Previous data collected from ICH using the homemade RASP system were in close agreement with that from other centers and were included in the collated dataset for $V^{\prime}{ }_{\operatorname{maxFRC}}$ prediction equations. ${ }^{9}$ Given that the mean $V_{\operatorname{maxFC}} \mathrm{Z}_{\text {- }}$ score for data collected in our laboratory using the RASP system $(n=283)$ was -0.52 , i.e. 0.88 Zscores higher than that from our recent Jaeger data, it is likely that the observed differences reflect differences in hardware and software rather than population differences or changes in practice.

This study was only possible because we retain full ethics approval to undertake lung function measurements in healthy infants and have always attempted to recruit a prospective control group for clinical research projects. In the past, many research groups prospectively recruited healthy controls, ${ }^{1,5-7,30-32}$ but during recent years there has been ongoing debate as to whether it is ethical to undertake lung function tests under sedation in healthy infants. Given the results from this study, it could be argued that it is unethical to undertake lung function tests in infants with lung disease (who are far more at risk of any sedation related adverse events than healthy children) without appropriate reference equations with which to interpret results. Indeed, had we not continued to recruit healthy controls prospectively after switching to commercially available equipment, our clinical and research data from the past 5 years would be potentially invalid. It is accepted that recruiting healthy infants to lung function studies is far more demanding and time consuming than enrolling those with lung disease, but in over 30 years of practice we have never observed an adverse event related to chloral sedation in a healthy infant, this group representing those at least risk from such events. ${ }^{33}$

The clinical implications of using inappropriate reference ranges can be seen from our results in infants with $\mathrm{CF}$. The use of published reference equations would have resulted in significant overdiagnosis of abnormal lung function, and over-estimation of the rate of change in lung function during the first two years of life. Such findings are particularly pertinent at a time when there is increased emphasis on early intervention studies and the need for objective outcome measures in 
early life. ${ }^{34}$ In addition to the anxiety caused to parents, reports of apparently 'diminished' LF results in asymptomatic infants and young children could result in further potentially invasive investigations and more aggressive treatment than would be warranted if results have been underestimated, whereas errors in the reverse direction could lead to false reassurance and undertreatment.

The fact that we needed to further adjust published equations for either length or age to obtain adequate fit in healthy infants emphasizes the importance of ensuring that future reference equations are based on a large number of healthy infants with a relatively even spread over the entire age range of interest, which has not always been the case previously. Derivation of equations from datasets which include just a few individuals at the extremes, or extrapolation of predictions beyond the age or length range studied in health is particularly likely to introduce errors when interpreting results from infants with lung disease. ${ }^{35}$

Although the current study represents the largest collection of normative data using Jaeger infant equipment, given the rapid rate of growth and need for sex-specific equations, numbers are still insufficient to create reliable reference equations de novo. In addition, such equations would be based in data from a single centre which may not be applicable elsewhere. ${ }^{35}$ Consequently, until further multi-centre data can be collated, we have chosen to express the results as Z-scores using available prediction equations to adjust for sex, age and body size, before deriving an equipmentspecific adjustment factor. We will continue to collect normative data and would welcome contributions from other centers that are using the same equipment to study healthy children during the first 2 years of life. In the meantime, those using the Jaeger infant equipment are urged to interpret their data cautiously and consider applying the enclosed corrections. It must be emphasized that the correction factors presented are specific to the Jaeger equipment in our 
laboratory, and that there is an urgent need for users of other commercially available systems to undertake a similar exercise.

CONCLUSIONS AND FUTURE DIRECTIONS: The marked differences observed between FEFV data from healthy infants when collected with modern commercially available infant lung function equipment and published reference data emphasize the need for prospective recruitment of healthy controls during clinical research studies and for the development of device-specific normative data with which to interpret results from infants with lung disease. If infant lung function tests are to have any significant future role, a concerted effort from members of the ATS/ERS working group on infant and lung function tests to present the rationale and safety data to support recruitment of healthy infants for lung function tests, and discourage usage of such tests in the absence of adequate controls, is urgently needed in order to address the recent barriers introduced by the FDA and certain ethics committees. 


\section{ACKNOWLEDGEMENTS}

The authors thank the infants and their parents who participated in this study. We also thank Dr Padmaja Subbarao, Dr Amit Gupta, Ms Joanne Chittenden and Ms Alicia Bolton who provided valuable assistance in subject recruitment and performing the measurements. 


\section{REFERENCES}

1. Dezateux C, Lum S, Hoo AF, Hawdon J, Costeloe K, Stocks J. Low birth weight for gestation and airway function in infancy: exploring the fetal origins hypothesis. Thorax 2004; 59(1):6066.

2. Hoo AF, Dezateux C, Henschen M, Costeloe K, Stocks J. Development of airway function in infancy after preterm delivery. J Pediatr 2002; 141(5):652-658.

3. Young S, Arnott J, O'Keeffe PT, Le Souëf PN, Landau LI. The association between early life lung function and wheezing during the first 2 years of life. Eur Respir J 2000; 15(1):151-157.

4. Lum S, Hulskamp G, Merkus P, Baraldi E, Hofhuis W, Stocks J. Lung function tests in neonates and infants with chronic lung disease: forced expiratory maneuvers. Pediatr Pulmonol 2006; 41(3):199-214.

5. Lum S, Gustafsson P, Ljungberg $\mathrm{H}$ et al. Early detection of cystic fibrosis lung disease: multiplebreath washout versus raised volume tests. Thorax 2007; 62(4):341-347.

6. Ranganathan S, Stocks J, Dezateux C et al. The evolution of airway function in infancy and early childhood following clinical diagnosis of cystic fibrosis. Am J Respir Crit Care Med 2004; 169:928-933.

7. Friedrich L, Pitrez PM, Stein RT, Goldani M, Tepper R, Jones MH. Growth rate of lung function in healthy preterm infants. Am J Respir Crit Care Med 2007; 176(12):1269-1273.

8. Jones MH, Howard J, Davis S, Kisling J, Tepper RS. Sensitivity of spirometric measurements to detect airway obstruction in infants. Am J Respir Crit Care Med 2003; 167(9):1283-1286.

9. Hoo AF, Dezateux C, Hanrahan J, Cole TJ, Tepper R, Stocks J. Sex-specific prediction equations for $\mathrm{V}_{\operatorname{maxFRC}}$ in infancy: a multi-center collaborative study. Am J Respir Crit Care Med 2002; 165:1084-1092.

10. Jones M, Castile R, Davis S et al. Forced expiratory flows and volumes in infants. Am J Respir Crit Care Med 2000; 161:353-359.

11. ATS_ERS Consensus Statement, Lum S, Stocks J et al. Raised volume forced expirations in infants: Recommendations for current practice. Am J Respir Crit Care Med 2005; 172(11):1463-1471.

12. Sly P, Tepper R, Henschen M, Gappa M, Stocks J. Standards for infant respiratory function testing: Tidal forced expirations. Eur Respir J 2000; 16:741-748. 
17. Borrego LM, Stocks J, Leiria-Pinto $\mathrm{P}$ et al. Lung function and clinical risk factors for asthma in infants and young children with recurrent wheeze. Thorax 2009; 64(3):203-209.

18. Gupta A, Stocks J, Lum S, Huertas A, Costeloe K, Hoo AF. EPICure 2: Airway function in extreme preterm infants at 1year. Arch Dis Child 94[Suppl 1], A41-A42. 2009.

Ref Type: Abstract

19. Lum S, Hoo AF, Stocks J. Effect of airway inflation pressure on forced expiratory maneuvers from raised lung volume in infants. Pediatr Pulmonol 2002; 33(2):130-134.

20. Lum S, Hoo AF, Stocks J. Influence of jacket tightness and pressure on raised lung volume forced expiratory maneuvers in infants. Pediatr Pulmonol 2002; 34(5):361-368.

21. Lum S, Hulskamp G, Hoo AF, Ljungberg H, Stocks J. Effect of raised lung volume technique on subsequent measures of $V^{\prime}{ }_{\text {maxFRC }}$ in infants. Pediatr Pulmonol 2004; 38:146-154.

22. Alexander FE, Anderson TJ, Brown HK et al. 14 years of follow-up from the Edinburgh randomised trial of breast-cancer screening. Lancet 1999; 353(9168):1903-1908.

23. Brown HK, Prescott RJ. Applied Mixed Models in Medicine. John Wiley and sons; 1999.

24. Edwards LJ. Modern statistical techniques for the analysis of longitudinal data in biomedical research. Pediatric Pulmonology 2000; 30(4):330-344.

25. Hulskamp G, Lum S, Hoo AF et al. V'maxFRC - validation of a new commercially available equipment. European Respiratory Journal 20[Suppl 38], 224s. 2002. 
26. Bates JHT, Turner MJ, Lanteri CJ, Jonson B, Sly PD. Measurement of flow and volume. In: Stocks J, Sly PD, Tepper RS, Morgan WJ, editors. Infant Respiratory Function Testing. 1 ed. New York: John Wiley \& Sons, Inc.; 1996 p. 81-116.

27. Kunzli N, Kuna-Dibbert B, Keidel D et al. Longitudinal validity of spirometers--a challenge in longitudinal studies. Swiss Med Wkly 2005; 135(33-34):503-508.

28. Orfei L, Strachan DP, Rudnicka AR, Wadsworth ME. Early influences on adult lung function in two national British cohorts. Arch Dis Child 2008; 93(7):570-574.

29. Broughton SJ, Sylvester KP, Page CM, Rafferty GF, Milner AD, Greenough A. Problems in the measurement of functional residual capacity. Physiol Meas 2006; 27(2):99-107.

30. Castile RG, Iram D, McCoy KS. Gas trapping in normal infants and in infants with cystic fibrosis. Pediatr Pulmonol 2004; 37(5):461-469.

31. Linnane BM, Hall GL, Nolan G et al. Lung function in infants with cystic fibrosis diagnosed by newborn screening. Am J Respir Crit Care Med 2008; 178(12):1238-1244.

32. Tepper RS, Williams-Nkomo T, Martinez T, Kisling J, Coates C, Daggy J. Parental smoking and airway reactivity in healthy infants. Am J Respir Crit Care Med 2005; 171(1):78-82.

33. Gaultier C, Fletcher ME, Beardsmore C, England S, Motoyama E. Respiratory function measurements in infants: measurement conditions. Working Group of the European Respiratory Society and the American Thoracic Society. Eur Respir J 1995; 8(6):1057-1066.

34. Davis SD, Ratjen F. Reduced lung function in cystic fibrosis: a primary or secondary phenotype? Am J Respir Crit Care Med 2008; 178(1):2-3.

35. Stanojevic S, Wade A, Stocks J. Reference values for lung function: past, present and future. Eur Respir J. In press. 


\section{FIGURE LEGENDS}

Figure 1: FEFV data from healthy infants expressed as Z-scores plotted against length at test, A) according to published reference equations $\left(\mathrm{FEV}_{0.5}, \mathrm{FEF}_{25-75}\right.$ using Jones et al, ${ }^{10}$ and $\mathrm{V}^{\prime}{ }_{\operatorname{maxFRC}}$ according to $\mathrm{Hoo}$ et $\mathrm{al}^{9}$ and $\mathrm{B}$ ) after adjusting for the Jaeger equipment used. Open circles represent girls and closed circles are boys.

The Upper and Lower Limit of the Normal range (ULN and LLN, as defined by \pm 1.96 Z-scores) are shown. Data from only one test occasion per child are shown on these graphs.

Figure 2: Comparison of FEFV data from healthy infants (HC) and those with CF; A) before and B) after adjustment for equipment.

The solid lines denote the mean value for the group and the Upper and Lower Limit of the Normal range (ULN and LLN, as defined by \pm 1.96 Z-scores) are shown. Data from only one test occasion per child are shown on these graphs.

Reliance on published reference would have resulted in $17 \mathrm{CF}$ infants and $9 \mathrm{HC}$ being classified as having 'abnormal' $\mathrm{FEV}_{0.5}(<-1.96 \mathrm{Z}$-scores). After adjusting for equipment, 41\% (7/17) of CF infants with 'abnormal' results were shown to have been mis-classified. Similarly for forced expiratory flows, $20(45 \%)$ and $25(49 \%) \mathrm{CF}$ infants were identified as having diminished $\mathrm{FEF}_{25-75}$ and $V^{\prime}$ maxFRC, respectively, when using the unadjusted published references, of which $65 \%(13 / 20)$ and $80 \%(20 / 25)$ would have been mis-classified. 
Table 1: Comparison of FEFV data between healthy infants and those with CF, before and after adjusting the prediction equations.

\begin{tabular}{|c|c|c|c|c|c|c|}
\hline & \multicolumn{3}{|c|}{ Published reference } & \multicolumn{3}{|c|}{ Adjusted for equipment } \\
\hline & & & Mean $(95 \% \mathrm{CI})$ difference & & & Mean $(95 \%$ CI $)$ adjusted \\
\hline & $\mathrm{CF}$ & Control & (CF-Control) & $\mathrm{CF}$ & Control & difference (CF-Control) \\
\hline $\mathrm{n}$ & 96 & $87^{\mathrm{d}}$ & & 96 & $87^{\mathrm{e}}$ & \\
\hline $\mathrm{FVC}^{\mathrm{a}}$ & $-1.27(1.16)^{\mathrm{c}}$ & $-0.38(1.11)^{*}$ & $-0.89(-1.24 ;-0.54)^{* * *}$ & $-0.97(1.18)^{c}$ & $0.02(1.14)$ & $-1.00(-1.34 ;-0.66)^{* * *}$ \\
\hline $\mathrm{FEV}_{0.5}{ }^{\mathrm{a}}$ & $-1.65(1.42)^{\mathrm{c}}$ & $-0.58(0.99)^{* * *}$ & $-1.06(-1.43 ;-0.69)^{* * *}$ & $-1.18(1.35)^{\mathrm{c}}$ & $-0.03(0.90)$ & $-1.15(-1.50 ;-0.80)^{* * *}$ \\
\hline $\mathrm{FEF}_{25-75}{ }^{\mathrm{a}}$ & $-1.77(1.56)^{\mathrm{c}}$ & $-0.98(1.04)^{* * *}$ & $-0.79(-1.20 ;-0.38)^{* * *}$ & $-0.76(1.52)^{c}$ & $0.10(1.00)$ & $-0.86(-1.25 ;-0.46)^{* * *}$ \\
\hline$V_{\operatorname{maxFRC}}^{\mathrm{b}}$ & $-1.65(1.24)$ & $-1.41(1.08)^{* * *}$ & $-0.25(-0.59 ; 0.09)$ & $-0.37(1.17)$ & $0.00(0.92)$ & $-0.38(-0.68 ;-0.07)^{*}$ \\
\hline
\end{tabular}

Data expressed as Mean (SD) Z-scores; * $\mathrm{p}<0.05 ; * * *: \mathrm{p}<0.001$

${ }^{\text {a Jones }} 2000$ AJRCCM, with smoking during pregnancy status set to $0 .{ }^{10}$

${ }^{\text {b}}$ Hoo 2002 AJRCCM. ${ }^{9}$

c $\mathrm{n}=85$;

d significance of difference based on comparison of Z-score results from healthy controls and that predicted from published reference equations (i.e mean (SD) of 0 (1). 


\section{Page 49 of 50}

Lung function in healthy infants

Lum et al

By definition, one would expect $95 \%$ of a healthy population to fall within \pm 1.96 SD or Z-scores of predicted values. ${ }^{15,32}$ Before adjustment (d), all FEFV outcomes from healthy controls were significantly lower than predicted from published reference values; whereas after adjustment (e), the mean (SD) for all results approximated 0 (1). When compared with controls, $\mathrm{FVC}, \mathrm{FEV}_{0.5}$ and $\mathrm{FEF}_{25-75}$ were significantly lower in infants with $\mathrm{CF}$, both before and after adjustment. Although the magnitude of group differences were slightly greater after adjustment, the number of individual infants with CF who were classified with abnormal lung function (<1.96 Z-scores) was lower (see Fig 2). 
Table 2a: Adjusted prediction equations taking length into account (Jaeger Z-scores)

\begin{tabular}{ll}
\hline Adjusted zFVC & $=\mathrm{zFVC}_{\text {(Jones) }}+(0.057 \times$ length, $\mathrm{cm})-3.90$ \\
Adjusted $\mathrm{zFEV}_{0.5}$ & $=\mathrm{zFEV}_{0.5(\text { Jones })}+(0.058 \times$ length, $\mathrm{cm})-3.83$ \\
Adjusted $\mathrm{zFEF}_{75}$ & $=\mathrm{zFEF}_{75 \text { (Jones) }}+(0.037 \times$ length, $\mathrm{cm})-1.94$ \\
Adjusted $\mathrm{zFEF}_{25-75}$ & $=\mathrm{zFEF}_{25-75(\text { Jones })}+(0.040 \times$ length, $\mathrm{cm})-1.94$ \\
Adjusted $\mathrm{V}_{\text {maxFRC }}$ & $=\mathrm{z} V_{\text {maxFRC (Hoo) }}^{\prime}+(0.074 \times$ length, $\mathrm{cm})-4.17$
\end{tabular}

Table 2b: Adjusted prediction equations taking age into account

\begin{tabular}{|c|c|}
\hline Adjusted zFVC & $=\mathrm{zFVC}_{(\text {Jones })}+(0.018 *$ age, weeks $)-0.538$ \\
\hline Adjusted $\mathrm{zFEV}_{0.5}$ & $=\mathrm{zFEV}_{0.5(\text { Jones })}+(0.018 *$ age, weeks $)-0.341$ \\
\hline Adjusted $\mathrm{zFEF}_{75}$ & $=\mathrm{zFEF}_{75 \text { (Jones) }}+(0.010 *$ age, weeks $)-0.347$ \\
\hline Adjusted $\mathrm{zFEF}_{25-75}$ & $=\mathrm{zFEF}_{25-75(\text { Jones })}+(0.011 *$ age, weeks $)-0.491$ \\
\hline Adjusted V' ${ }_{\text {maxFRC }}$ & $=\mathrm{z} V_{\operatorname{maxFRC}(\mathrm{Hoo})}^{\prime}+(0.020 *$ age, weeks $)-0.355$ \\
\hline
\end{tabular}

Age and length contributed equally and significantly to these models. After adjusting for length or age, addition of the other variable did not add significantly to the model, and length was chosen in preference to age to prevent any bias due to restricted growth when applying such equations to children with lung disease. 